Bangladesh J. Bot. 50(3): 755-761, 2021 (September) SpecialＤOI: https://doi.org/10.3329/bjb.v50i5.56426

\title{
SOIL CONSERVATION EFFECTS AND ECONOMIC BENEFIT OF DIFFERENT CROPS CULTIVATED ON GENTLE SLOPES IN THE SOUTH MINING AREA, CHINA
}

\author{
Dong Wang ${ }^{1}$, Rui Zeng ${ }^{\S}$, Zhixin Hu ${ }^{\S}$, Xiang Li ${ }^{1}$, Yuan Guo ${ }^{2}$, \\ Pan Yang, Wei She ${ }^{1}$ and Wanli Kang ${ }^{3}, \S, *$ \\ Hunan Airbluer Environmental Protection Technology Co. Ltd., \\ Changsha, 410000 Hunan, China
}

Keywords: Kenaf, Ramie, Gentle slope, Erosion modulus, Soil conservation, Runoff coefficient

\begin{abstract}
The runoff and sand production of two fibre crops, Hibiscus cannabinus L. (Kenaf) and Boehmeria nivea L. (Ramie), under natural rainfall conditions in natural gentle sloping (less than $10^{\circ}$ ) farmlands in a in mining area were studied. Abelmoschus esculentus L. Moench (Okra) and Zea mays L. (Maize) plants were used as the control. The results showed the rank of soil erosion moduli and average runoff coefficients among tested plant species were: okra plot > maize plot $(\mathrm{CK})>$ kenaf plot $>$ ramie plot. Economic benefits were harvested from different crop treatments, with the maximum of 25,157 CNY/ha for kenaf,19,440 CNY/ha for ramie, 16,858.6 $\mathrm{CNY} /$ ha for okra, and 18,332 CNY/ha for corn (CK) treatment. Results suggest that planting kenaf and ramie on gentle slopes in eastern Hunan is beneficial to water and soil conservation and can effectively prevent soil erosion.
\end{abstract}

\section{Introduction}

Soil erosion is the main factor that leads to the ecological deterioration of the environment and the decline of land productivity (Yu and Lin 2009, Cai et al. 2020). Due to heavy rainfall and a large number of construction projects in sloping farmlands in southern China, the problem of soil erosion is rather serious and complicated (Zhang et al. 2010). There are approximately 1.6 million $667 \mathrm{~m}^{2}$ of sloping lands in the south, accounting for 50\% of the total area of arable sloping lands in China. Arable sloping lands are the land category suffering the most serious soil erosion in southern China, but at the same time, they are important sediment source for the Yangtze River ( $\mathrm{Li}$ and Tu 2010, Kang et al. 2012). Over the years, due to both natural and human damages, sloping farmlands have become an area with the most extensive and high degree of soil erosion in southern China, and therefore it is one of the most problematic areas for soil erosion control in China (Li et al. 2020). Kenaf has a long planting history on sloping farmlands in southern China. Because of its lush foliage and well-developed root system, it can effectively reduce soil erosion and surface runoff, and has significant effects on soil erosion control. It is an excellent species for water and soil conservation (Zhou et al. 2019). Kenaf is not only used for harvesting its fibres, but also serve as high-protein feed (Liu and Yang 2018). In the present study, the soil and water loss on a sloping farmland planted with kenaf and other plant species were investigated and useful information for controlling soil and water loss on slope farmlands by planting kenaf were tried to provide.

\footnotetext{
*Author for correspondence: <xyz111com@163.com>. ${ }^{1}$ Ramie Research Institute, Hunan Agricultural University, Hunan 410128, China. ${ }^{2}$ Institute of Best Fiber Crops, Chinese Academy of Agricultural Sciences, 410000, Hunan, China. ${ }^{3}$ Grassland Resources Protection Center of Shaoyang, Shaoyang, 422000, Hunan, China. ${ }^{\S}$ Contributed equally to this work.
} 


\section{Materials and Methods}

The experiment was carried out in Qibaoshan County, Liuyang City, Hunan Province (N $28^{\circ} 17^{\prime} 35.34 "$ ", E 113'51'16.884", altitude: 100.93m). The soil is mountain red soil and yellow soil. The test area is located in a subtropical humid monsoon climate zone, with an annual average temperature of $16.5^{\circ} \mathrm{C}$, and rainfall of $1907.98 \mathrm{~mm}$ (Table 1), an average relative humidity of $82 \%$, and annual sunshine hours of $1,529 \mathrm{hrs}$.

The slope of the test site is 8 degrees. The size of the runoff plots is $2.5 \times 18 \mathrm{~m}$, and there are a total of eight runoff observation plots, with two $1 \times 1 \times 1 \mathrm{~m}$ runoff ponds built under each plot.

Table 1. Precipitation at the test site in 2019.

\begin{tabular}{lcccccccccccc}
\hline & Jan & Feb & Mar & Apr & May & Jun & Jul & Aug & Sep & Oct & Nov & Dec \\
\hline Rainfall (mm) & 91.71 & 163.46 & 183.94 & 178.38 & 286.67 & 365.01 & 352.05 & 60.16 & 7.84 & 87.2 & 79.11 & 52.45 \\
\hline
\end{tabular}

The experiment included three treatments and one CK (maize). The planting of each plot was of the same manner. Ramie was planted with a surrounding area of $0.5 \times 0.5 \mathrm{~m}$. Kenaf was planted in rows with spacing of $30 \mathrm{~cm}$, and $1.5-2.0 \mathrm{~kg}$ of seeds was used per $667 \mathrm{~m}^{2}$. Each treatment contained three replicates:

(i) Kenaf plot: Plants were harvested once in late September. The by-product such as young shoots and leaves after harvesting fibers can be used as feed. Kenaf fibers are materials for making artificial planks.

(ii) Ramie plot: Ramie fibres were harvested using standard harvesting method at usual times, three times a year. The first season of ramie was harvested in early June; the second in early August; and the third in late October. After harvesting the by-product young shoots and ramie leaves the fibres can be used as feed. The stalk is the raw material for producing active carbon by burning, and the shell is used as the medium for cultivating edible fungi.

(iii) Okra plot: plants were harvested when they reached the mature stage, then the yield and quality are both good.

(iv) Maize plot: Seeds were planted in mid-April, with a surrounding area of $30 \times 40 \mathrm{~cm}$, and served as the control (CK). After the maize plants matured, the cobs were harvested, and the stalk can be used for feeding livestock.

Plant height measurement: The 5 plants were selected in each plot, and their natural height was measured once a month with a tape.

The coverage was measured by a needle-based method. In a $1 \mathrm{~m}^{2}$ sample square, with the help of the steel tape and the markings on the sample square rope, vertical needles ( $2 \mathrm{~mm}$ in diameter) were dropped with an interval of $10 \mathrm{~cm}$ (100 needles in total). If the needle touched the plant, it was counted as ' $\mathrm{O}$ '; if there is no contact, it was counted as ' $\mathrm{X}$ '. The numbers of ' $\mathrm{O}$ ' points and ' $\mathrm{X}$ ' points were counted and the coverage (\%) was calculated (Zhang and Cheng 2017).

The ratio of the volume of rainwater in the runoff pool of the plot to the total rainfall volume of the plot (rainfall times the area of the plot) is the runoff coefficient (Soil and water conservation test specification 2007 (Cheng et al. 2009).

Average runoff coefficient: The sum of each runoff coefficient divided by the number of times is the average runoff coefficient (Liu and Yang 2018, Zhang and Cheng 2017). 


\section{Results and Discussion}

Results presented in Fig. 1 showed that kenaf, and maize (CK) plants displayed an S-growth type growth and was slow initially, then faster and slower again. For okra plants, as they were harvested when the plants were $65 \mathrm{~cm}$ in height, the growth rate was high and substantially uniform, showing a linear growth type. The kenaf plots had basically the same growth rate since the first top dressing. When the plant height was approximately $380 \mathrm{~cm}$, the growth rate began to decline. This was also the time when the fibres reached maturity. The average height of okra plants was approximately $70 \mathrm{~cm}$, while the height of maize plants was up to $260 \mathrm{~cm}$.

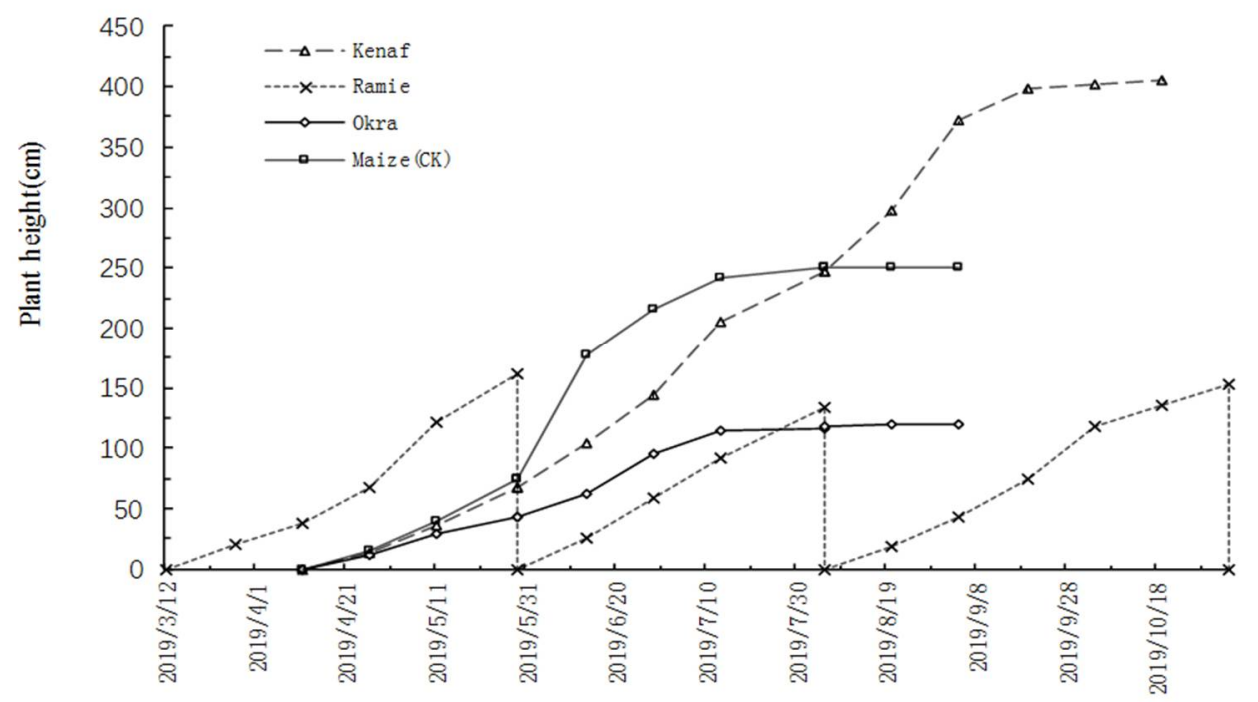

Fig. 1. Plant height dynamic in different treatment plot.

Vegetation coverage plays a significant role in the prevention and control of soil erosion on slopes; especially the vegetation coverage percentage of plants on lands in the rainy season is one of the direct factors affecting the efficacy of soil and water conservation on slopes. As can be seen from Fig. 2, in terms of the overall coverage, kenaf plot $>$ ramie plot $>$ maize plot (ck) $>$ okra plot. The kenaf plot was of a large coverage, and therefore, it may effectively intercept rainwater and reduce soil erosion in spring when there is more rain. The coverage of the kenaf plot reached $90 \%$ as early as May, before the maturation. Later, the lower leaves fell, and the coverage began to decline; yet as the plant continued to grow taller, the coverage increased again. For the ramie plot, the fibres were harvested at the beginning of June, the plot coverage decreased. New tillers grew rapidly, and the coverage reached over $70 \%$ within one month. The ramie stalks and leaves dropped during harvest covering the ground and reduced the scouring of rainwater on the ground. The growth period of the maize plants lasted only four months, and the maximum coverage reached 90\%. By August, the plants began to mature, the leaves withered, and the coverage declined rapidly.

The statistical analysis of the erosion modulus of each plant species after each rainfall is shown in Table 2. When the rainfall in May 19 and June 21, was compared the rainfall was 51.6 and 57.1 $\mathrm{mm}$ in May 19 and June 21, respectively. While the rainfall values were similar, the rainfall intensities on these two days $(0.35 \mathrm{~mm} / \mathrm{min}$ on May 19 and $0.13 \mathrm{~mm} / \mathrm{min}$ on June 21) showed a 2.7 times difference. The erosion module of the kenaf plot, ramie plot, okra plot, maize plot (CK) on 
May 19 were 1.59, 0, 1.76 and 1.64 times of the corresponding values on June 21, indicating that the rain intensity is a key factor affecting the runoff scouring force. As higher rain intensity leads to a higher runoff scouring force, it is easier to scour the underlying surface, resulting in an increase in sediment amount. Although rainfall may last for a long time, due to low rainfall intensity, the rain has enough time to penetrate the soil, generating only a small amount of sediment. Under different rainfall conditions, the rank of erosion module in each plot was: Okra plot > maize plot $(\mathrm{CK})>$ ramie plot > kenaf plot and the soil erosion modules among these plots were significantly different.

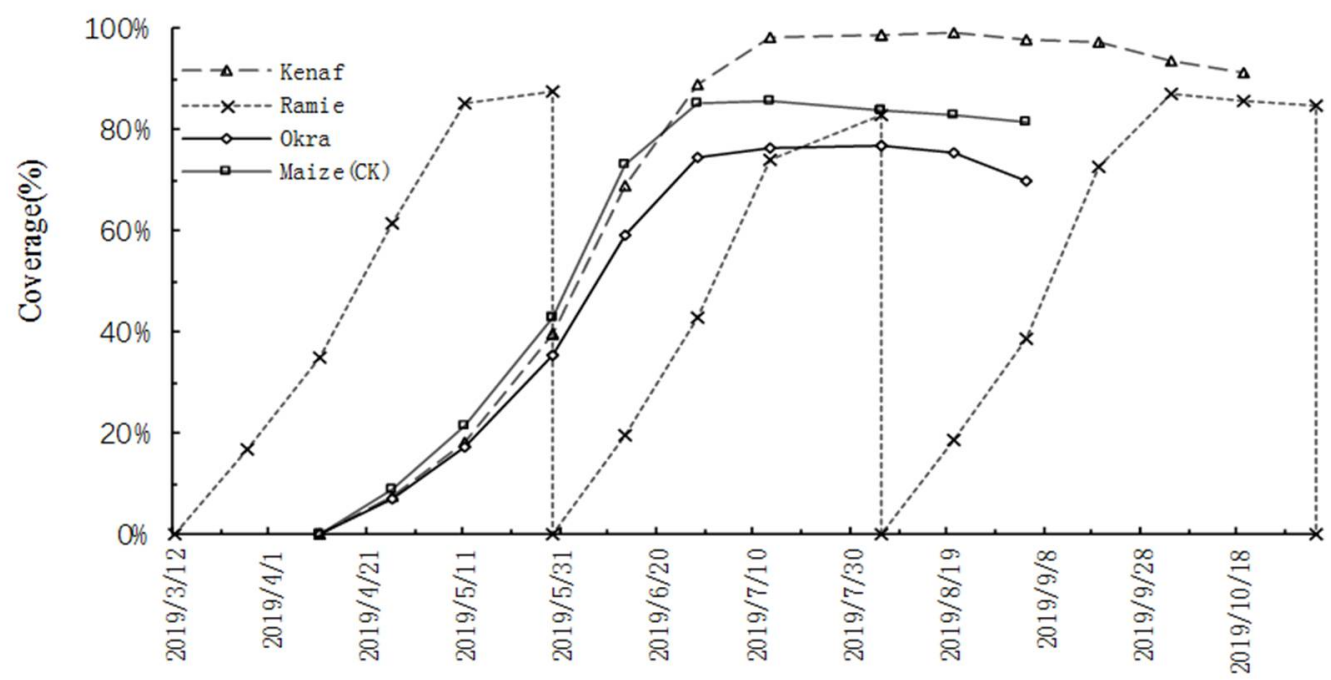

Fig. 2. Coverage dynamic in different plots.

Table 2. Soil erosion module of different plots under different rainfall conditions.

\begin{tabular}{lcccccc}
\hline Date & Rainfall & Rainfall intensity & \multicolumn{4}{c}{ Erosion modulus $\left(\mathrm{t} / \mathrm{km}^{2}\right)$} \\
\cline { 4 - 7 } & $(\mathrm{mm})$ & $(\mathrm{mm} / \mathrm{min})$ & Kenaf & Ramie & Okra & Maize $(\mathrm{CK})$ \\
\hline May 12 & 61.7 & 0.24 & $62.7 \pm 4$ & 0 & $164.3 \pm 15$ & $187.5 \pm 13$ \\
May 19 & 51.6 & 0.35 & $84.3 \pm 8$ & 0 & $237.0 \pm 21$ & $194.1 \pm 13$ \\
Jun 8 & 68.2 & 0.17 & $75.4 \pm 5$ & $88.7 \pm 6$ & $163.2 \pm 12$ & $144.8 \pm 9$ \\
Jun 21 & 57.1 & 0.13 & $52.8 \pm 7$ & $43.8 \pm 5$ & $134.6 \pm 11$ & $118.2 \pm 12$ \\
Jun 22 & 86.2 & 0.21 & $212.4 \pm 14$ & $282.5 \pm 18$ & $568.1 \pm 77$ & $449.7 \pm 50$ \\
Jul 7 & 46.5 & 0.12 & 0 & 0 & $14.7 \pm 1$ & 0 \\
Jul 8 & 124.3 & 0.41 & $1043.6 \pm 27$ & $973.5 \pm 22$ & $2230.7 \pm 62$ & $1648.5 \pm 70$ \\
Analysis of & \multicolumn{5}{c}{ F value } \\
variance & Among rainfall conditions & & $25.9^{*}$ & & \\
\multicolumn{7}{c}{ Erosion modulus } \\
\hline
\end{tabular}

Different letters after the values of same column indicate significant differences at the $p<0.05$ level. '*' and ‘**' indicate the 0.05 level and 0.01 level, respectively. 
The runoff coefficients of plots with different plants were different (Table 3). The average runoff coefficient of the okra plot was $0.26 \%$; the average runoff coefficient of the maize plot (CK) was $0.23 \%$; the average runoff coefficient of the ramie plot was $0.13 \%$; and the average runoff coefficient of the kenaf plot was $0.15 \%$. Different plant species had different functions in shedding floods. In the case of low rainfall intensity, plants had a greater impact on runoff. Especially when the rainstorm intensity was high and the duration was short, the vegetation could play a significant role in cutting peaks and reducing floods.

Table 3. Runoff coefficients of different plots under different rainfall conditions.

\begin{tabular}{lcccccc}
\hline Data & \multirow{2}{*}{$\begin{array}{c}\text { Rainfall } \\
(\mathrm{mm})\end{array}$} & $\begin{array}{c}\text { Rainfall } \\
\text { intensity } \\
(\mathrm{mm} / \mathrm{min})\end{array}$ & Kenaf & Ramie & Okra & Maize (CK) \\
\cline { 6 - 7 } & & 0.24 & $0.21 \pm 0.03$ & 0 & $0.32 \pm 0.06$ & $0.34 \pm 0.08$ \\
May 12 & 61.7 & 0.35 & $0.28 \pm 0.04$ & 0 & $0.39 \pm 0.08$ & $0.37 \pm 0.07$ \\
May 19 & 51.6 & $0.17 \pm 0.01$ & $0.24 \pm 0.03$ & $0.18 \pm 0.01$ & $0.14 \pm 0.03$ \\
Jun 8 & 68.2 & 0.17 & $0.13 \pm 0.03 \pm 0.03$ \\
Jun 21 & 57.1 & 0.13 & $0.12 \pm 0.01$ & $0.21 \pm 0.03$ & $0.16 \pm 0.04$ & $0.13 \pm 0.07$ \\
Jun 22 & 86.2 & 0.21 & $0.14 \pm 0.02$ & $0.26 \pm 0.04$ & $0.32 \pm 0.06$ & $0.28 \pm 0.07$ \\
Jul 7 & 46.5 & 0.12 & 0 & 0 & $0.06 \pm 0.01$ & 0 \\
Jul 8 & 124.3 & 0.41 & $0.19 \pm 0.04$ & $0.22 \pm 0.04$ & $0.42 \pm 0.07$ & $0.35 \pm 0.09$ \\
Analysis of & \multicolumn{7}{c}{ Among rainfall conditions } & F value & $4 *$ & $3.1 *$ \\
variance & Runoff coefficients among treatments & & & \\
\hline
\end{tabular}

Different letters after the values of same column indicate significant differences at the $\mathrm{p}<0.05$ level. '*' and '**' indicate the 0.05 level and 0.01 level, respectively.

Water retention capacity and soil consolidation capacity are two of the important indicators to measure the effect of plant-based water and soil conservation strategies. The water retention capacity and soil consolidation capacity of the ramie plot were 42.2 and $49.4 \%$, respectively, which were the best among 4 plots (Table 3 ). The water retention capacity and soil consolidation capacity of the okra plot were -14.9 and $-28.1 \%$, respectively, which were the worst. Under natural rainfall conditions, the ramie plot showed the best water retention and soil consolidation capacities, followed by the kenaf plot, and both plots showed significantly better soil erosion control capacities than that of the maize plot (CK).

Among the three treatment plots, the kenaf plot had the highest economic efficiency of 25,157 $\mathrm{kg} / \mathrm{ha}$, followed by the ramie plot with $19,440 \mathrm{~kg} / \mathrm{ha}$ (Unit in metric system), both higher than the control maize plot (Table 4).

Table 3. Water retention and soil consolidation capacities of different plots.

\begin{tabular}{lcccc}
\hline Treatment & Kenaf & Ramie & Okra & Maize $(\mathrm{CK})$ \\
\hline Water retention capacity & 33.5 & 42.2 & -14.9 & 0 \\
Soil consolidation capacity & 44.2 & 49.4 & -28.1 & 0 \\
\hline
\end{tabular}


Table 4. Economic yield and efficiency of plots with different utilization methods.

\begin{tabular}{lcccc}
\hline Benefit & Kenaf & Ramie & Okra & Maize (CK) \\
\hline Economic yield (kg/ha) & 5241 & 1944 & 12042 & 8333 \\
Price (CNY/kg) & 4.8 & 10 & 1.4 & 2.2 \\
Economic benefits (CNY/ha) & 25157 & 19440 & 16858.6 & 18332 \\
\hline
\end{tabular}

The rank of soil erosion modulus of different treatments was: okra plots $>$ maize plots (ck) $>$ the kenaf plots > ramie plots; the rank of runoff coefficient was: okra plots $>$ maize plot (ck) $>$ kenaf plots > ramie plots. Compared with the control (maize [ck] and okra plots), the water retention capacity and soil consolidation capacity of the ramie treatment were the best 42.2 and $49.4 \%$, respectively, and the okra treatment was the worst $-14.9 \%$ (retention capacity) and $-28.1 \%$ (soil consolidation).

Economic benefits were harvested from different crop treatments, with the maximum of 25,157 $\mathrm{CNY}$ /ha for kenaf,19,440 CNY/ha for ramie,16,858.6 CNY/ha for okra, and 18,332 CNY/ha for corn $(\mathrm{CK})$ treatment.

This experiment only measured one year's rainfall and soil erosion data, and there were six rainfalls with obvious soil erosion in each treatment, mainly from May to October. The amount of soil loss in the kenaf plot was $2295 \mathrm{t} / \mathrm{km}^{2}$.a. It is speculated that it was mainly due to the large rainfall and rainfall intensity in the year of the experiment. Moreover, the plot was newly built, so the soil was disturbed by human beings to a lager degree (Li et al. 2014), resulting in a large amount of soil erosion in the first year. For the okra treatment, due to its relatively poor water retaining and soil consolidation capacities, the runoff and sediment volume were higher than the control (the maize plot). However, in terms of the whole plant growth period, the whole growth period of the okra plants was about 6 months in the year, whereas the whole growth period of the maize plants was only 4 months; but the effect of okra treatment on soil and water conservation was worse than that of the maize plot. The reason for this result might be due to rainfall in the southern China mainly from April to September, and heavy precipitation is prone to occur (Yang et al. 2004). The runoff processes in this experiment mainly happened from May to August. At this stage, the maize plants grew faster and the vegetation coverage of the plot was higher than the okra plot, so more serious soil erosion was observed in the okra plot. A secondary reason might be that the first five rainfalls were larger both in volume and intensity.

\section{Acknowledgements}

This work was financially supported by the Special funds for construction of innovative provinces in Hunan Province (high-tech industry science and technology innovation leading program, No.2020GK4094), National Key Research and Development Program for International Science and Technology Cooperation Projects (No.2017YFE9135300).

\section{References}

Cai XD, Zhou YY and Liu YJ 2020. Evaluation of the ecological benefits of different tillage measures on sloping cultivated land in the red soil area of southern China. Soil Water Conser. Res. 27(5): 281-287.

Cheng DB, Zuo CQ and Cai CF 2009. Characteristics of soil erosion and influencing factors of each rainfall on different lower mat surfaces. Grassland Sci. 9(29): 30-33.

Kang W L, Jie YC and Xing HC 2012. Soil and water conservation effects and economic benefits of ramie cultivation on sloping land in southern China. Soil Water Conser. Res. 19(3): 86-89. 
Li GF, Yang RX and Xie FQ 2020. Soil erosion characteristics of terracotta soil slopes under different land uses. J. Soil Water Conser. 34(2): 101-107.

Li GJ, Cui M, Zhou JX, Peng SY and Xie YM 2014. Study on the benefits of soil erosion control measures for water and soil conservation in the red soil region of southern China. J Soil Water Conser. 28(5): 1-5.

Li R and Tu XN 2010. Accelerating the control of soil erosion in the southern slope cultivated land by taking the development of ramie resources as a breakthrough. Inter. Sea Buckthorn Res. Develop. 8(1): 21-26.

Liu J and Yang LK 2018. Progress of research on soil and water conservation measures in sloping cultivated land in the southern mountains of China. Sci. Technol. Innov. 17: 100-101.

Soil and water conservation test specification. 2007. Ministry of Water Resources and Electric Power of the People's Republic of China Standard SD2 39-87.

Yang YS, Wang ZY and Chen X 2004. Research on soil and water conservation and ecological benefits of different utilization patterns of red soil slopes in southern China. J. Soil Water Conser. 18(5): 84-87.

Yu Y and Lin H 2009. Progress in the study of red soil erosion in China. Subtropical Soil Water Conser. 21(3): 34-38.

Zhang ZY, Wu YC and Yang J 2010. Research on runoff and nutrient loss in red soil slope cultivation. J. Hohai Univ. 8(2): 241-246.

Zhang PC and Cheng DB 2017. Research on soil erosion process and regulation in sloping cultivated land in southern China. J. Yangtze Acad. Sci. 34(3): 35-39.

Zhou YW, Dai CT and Liu YJ 2019. Effects of tillage measures and rain intensity on erosion of red soil slopes in southern China. J. Soil Water Conser. 33(2): 49-54.

(Manuscript received on 19 May, 2021; revised on 27 August, 2021) 